\title{
Hyperfibrinogenemia and Reduced Plasma Protein C Levels in HIV-Infected Patients
}

\author{
Allageya Yousif Khailfa Ahmed1, Enaam Abdelrhman Abdelgader², \\ Nasr Eldeen Ali Mohammed Gaufri1,3* \\ ${ }^{1}$ Hematology Department, Faculty of Medical Laboratory Science, Al Neelain University, Khartoum, Sudan \\ ${ }^{2}$ Department of Pathology, Faculty of Medicine, Al Neelain University, Khartoum, Sudan \\ ${ }^{3}$ Empower Women for Change Organization, Glasgow, Scotland \\ Email: *nasralimohammed@yahoo.com
}

How to cite this paper: Ahmed, A.Y.K., Abdelgader, E.A. and Gaufri, N.E.A.M. (2022) Hyperfibrinogenemia and Reduced Plasma Protein C Levels in HIV-Infected Patients. Journal of Biosciences and Medicines, 10, 72-81.

https://doi.org/10.4236/jbm.2022.103008

Received: December 25, 2021

Accepted: March 5, 2022

Published: March 8, 2022

Copyright (C) 2022 by author(s) and Scientific Research Publishing Inc. This work is licensed under the Creative Commons Attribution International License (CC BY 4.0).

http://creativecommons.org/licenses/by/4.0/

\begin{abstract}
Background: Heamatological problems have been associated with human immunodeficiency virus infection. Hypercoagulability, in particular, thrombosis is becoming more common in HIV-positive patients. Aim: The goals of this study were to determine levels of plasma fibrinogen, protein C, Hemoglobin, and ESR among Sudanese HIV-positive patients. Materials and Methods: This is a case-control study, for this investigation, a total of 100 participants were recruited for this study. Fifty people were diagnosed with HIV, 25 of whom were males (50 percent) and 25 of whom were females (50 percent), with an average age of 35.5 years. Further fifty healthy people, 26 (52\%) of whom were men and 24 (48\%) of whom were women, with a mean age of 37.1 years, matched the case group. Fresh Poor Plasma was obtained by centrifuging citrated venous blood samples at $3000 \mathrm{rpm}$ for 15 minutes. The fibrinogen level was determined using an automated coagulation analyzer. Total protein $\mathrm{C}$ level was measured by a fully-automated blood coagulation analyzer (SYSMEX CA-500'JAPAN). The haemoglobin parameter was measured from EDTA anticoagulant samples using the Sysmex KX 21-N automated haematological analyzer. In one hour, the ESR was done using a Westergren tube. Data was collected using a structured direct questionnaire. SPSS version 21 was used to analyse the data. Results: The current study discovered that in Sudanese HIV infection, the mean and standard deviation of plasma fibrinogen levels were statistically substantially higher than in the normal control group ( $370.5 \pm 67$ vs $214.7 \pm 21$ with P value 0.001 ). Protein C levels were statistically significantly lower in HIV positive patients compared with control group $(0.6 \pm 0.1$ vs $1.3 \pm 0.2$ with $\mathrm{P}$ value 0.001$)$. In HIV positive patients, haemoglobin was statistically substantially lower than in healthy people (10.8 \pm 1.8 vs $13.7 \pm 1.9$, $\mathrm{P}$ value 0.01 ). The erythrocyte sedimentation rate was statistically significantly higher in HIV positive patients than in the control
\end{abstract}


group, with (58.00 \pm 27 vs $7.68 \pm 3$ with P value 0.00$)$. Conclusions: HIV infected patients had higher plasma fibrinogen levels and lower haemoglobin levels than normal healthy control groups. In 16 percent of HIV positive patients, protein $\mathrm{C}$ deficiency was discovered. HIV-positive patients had significantly greater ESR.

\section{Keywords}

Hypercoagulable, HIV, Fibrinogen, Anemia, Protein C, ESR

\section{Introduction}

The human immunodeficiency virus is a retrovirus that infects immune system cells and kills or impairs them, resulting in opportunistic infections and cancer [1]. According to UNAIDS, 19 million persons in Eastern and Southern Africa (ESA) and Western and Central Africa (WCA) were living with HIV in 2015. New HIV infections reduced by 14 percent in ESA and $8 \%$ in WCA between 2010 and 2015, while AIDS-related fatalities fell by 38 percent and 10\%, respectively. In ESA, 54 percent of all HIV-positive people received antiretroviral medication (ART), whereas, in WCA, just 28 percent of all HIV-positive people received ART. Since 2010, new HIV infections among children in ESA have decreased by 66 percent, compared to a 31 percent decrease in WCA [2]. Hematological abnormalities are common manifestations of advanced HIV-1 infection that could potentially limit the use of some components of antiretroviral therapy regimens [3] [4]. Peripheral blood cytopenias have been observed even in the absence of chemotherapeutic therapy or opportunistic infections and malignancies, showing that HIV infection is directly associated with the generation of these hematological abnormalities [5]. Fibrinogen is a crucial component of the coagulation cascade and has been linked to coronary artery disease [6]. Its increased viscosity facilitates platelet aggregation, modulates endothelial function, and promotes smooth muscle proliferation and migration, all of which may contribute to the development of vascular dysregulation. Because fibrinogen is an acute phase reactant, the link between high fibrinogen levels and atherosclerosis may be mediated by inflammation [7] [8]. Natural anticoagulants' activity particularly protein C [9] and hemoglobin levels were found to be reduced, but plasma fibrinogen levels in HIV patients were inconsistent [10]. In this study, we assessed plasma fibrinogen, protein $\mathrm{C}$, hemoglobin, and erythrocyte sedimentation rate in Sudanese HIV patients.

\section{Materials and Methods}

This descriptive case-control study was carried out from September to December of 2016. In this study a total of 100 volunteers. Throughout the duration of the research, 50 HIV patients were detected using (ELSIA) techniques, with 25 (50\%) males and 25 (50\%) females attending Omdurman Teaching Hospital in 
Khartoum recognized as the case group. Between the case group and the seemingly healthy individuals, a total of 50 participants were matched by age and gender. There were 26 males (52\%) and 24 women in the typical control group (48 percent). All of the individuals' venous blood was gathered into anticoagulant tubes containing citrate. PPP (Platelet Poor Plasma) was made immediately away by centrifuging at $3000 \mathrm{rpm}$ for 15 minutes. An automated coagulation analyzer has been used to measure plasma fibrinogen levels (Thrombolyzer XRC Germany). Total protein C levels were measured by fully-automated blood coagulation analyser (SYSMEX CA-500'JAPAN). The ESR was performed using a Westergren tube in one hour. Hemoglobin level was measured from EDTA anticoagulated venous blood samples using an automated SYSMEX KX $21 \mathrm{~N}$ hematology analyzer (Japan).

\subsection{Data Collection and Analysis}

The data was gathered using a direct questionnaire and analyzed using the SPSS version 21 software. To compare the parameters in mean and standard division, the T-test was utilized. When the P-value is less than 0.05 , it is considered to be significant.

\subsection{Exclusion Criteria}

This study excluded patients with coagulopathy disorders, hepatic diseases, inflammatory diseases, cancer, or who were on heparin or warfarin therapy.

\subsection{Ethical Approval}

This study was approved by Al Neelain University's Faculty of Medical Laboratory Science's ethical board. All participants had to express their permission before any samples were taken.

\section{Result}

The current study revealed that the mean of fibrinogen levels was statistically significantly higher among HIV patients compared with that normal healthy control group (370.5 \pm 67.7 vs $214.7 \pm 21.2$ with P value 0.00 ) (Table $1 \&$ Figure 1 ).

Table 2 shows the mean and stander deviation of protein $C$ levels were statistically significantly lower in HIV patients in comparison with those normal healthy control group $(0.6 \pm 0.1$ vs $1.3 \pm 0.2$ with $P$ value 0.00$)$

Table 3 demonstrates that, as compared to the normal healthy control group,

Table 1. Comparison of Fibrinogen levels among HIV positive and normal control group study groups.

\begin{tabular}{ccccc}
\hline Parameters & Study group & Number & Mean \pm St deviation & P value \\
\hline \multirow{2}{*}{ Fibrinogen Levels } & Case group & 50 & $370.5 \pm 67.7$ & 0.00 \\
& Control group & 50 & $214.7 \pm 21.2$ & \\
\hline
\end{tabular}

P. value less than 0.05 is considered significant. 


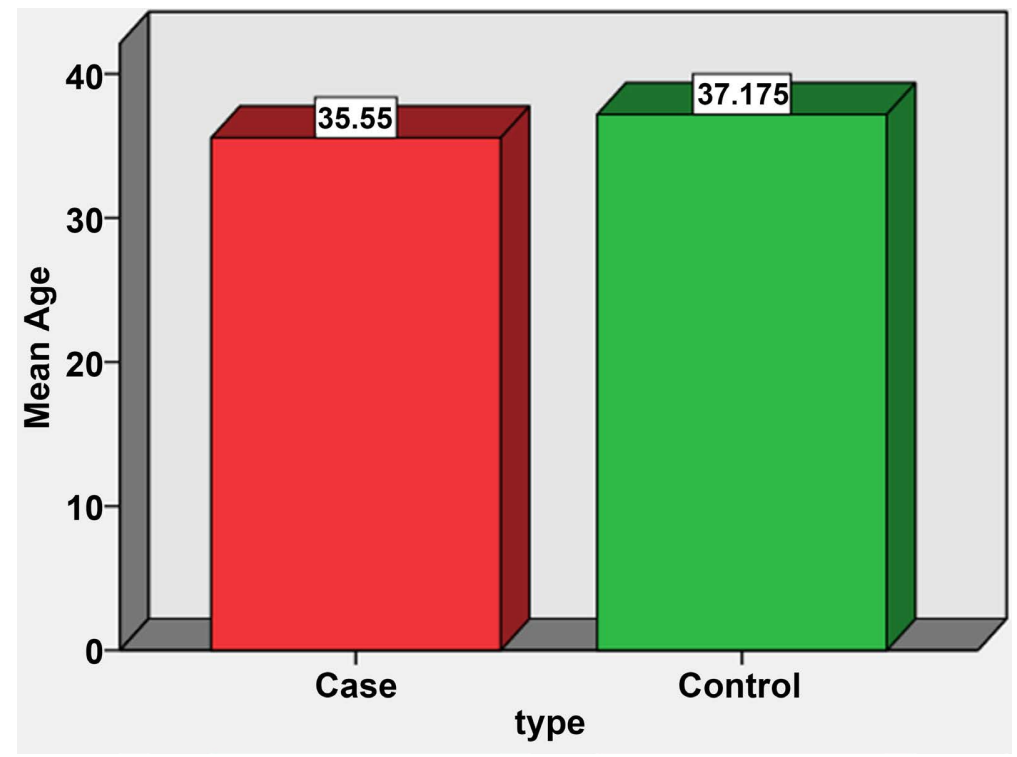

Figure 1. Distribution of age among study group.

Table 2. Comparison of protein C levels among HIV positive and normal control group study groups.

\begin{tabular}{ccccc}
\hline Parameters & Study group & Number & Mean \pm St deviation & P value \\
\hline \multirow{2}{*}{ Protein C Levels } & Case group & 50 & $0.6 \pm 0.1$ & 0.00 \\
& Control group & 50 & $1.3 \pm 0.2$ & \\
\hline
\end{tabular}

P. value less than 0.05 is considered significant.

Table 3. Comparison of haemoglobin levels among HIV positive and normal control group study groups.

\begin{tabular}{ccccc}
\hline Parameters & Study group & Number & Mean \pm St deviation & P value \\
\hline \multirow{2}{*}{ Hemoglobin Levels } & Case group & 50 & $10.8 \pm 1.8$ & \\
& Control group & 50 & $13.7 \pm 1.9$ & 0.01 \\
\hline
\end{tabular}

P. value less than 0.05 is considered significant.

the mean and standard deviation of haemoglobin levels were statistically significantly lower among Sudanese HIV positives (P value 0.01 ).

Table 4 shows that in Sudanese HIV positive individuals, the erythrocyte sedimentation rate was statistically significantly with (P value 0.00$)$ greater than in the control group.

\section{Discussion}

Infection with the human immunodeficiency virus (HIV) is frequently linked to an increased risk of venous [11] [12] [13] [14] and arterial thrombosis [15] [16] [17] [18]. Increased thrombotic risk has been associated with elevated plasma fibrinogen in inflammatory situations such as trauma and pregnancy. To our knowledge, only one published study has examined the association of inflammatory 
Table 4. Comparison of erythrocyte sedimentation rate among HIV positive and normal control group study groups.

\begin{tabular}{ccccc}
\hline Parameters & Study group & Number & Mean \pm St deviation & P value \\
\hline \multirow{2}{*}{ ESR mm/hour } & Case group & 50 & $58.00 \pm 27$ & 0.00 \\
& Control group & 50 & $7.68 \pm 3$ & \\
\hline
\end{tabular}

P. value less than 0.05 is considered significant.

markers with mortality in HIV-infected individuals in the HAART era [19]. The goal of this study was to determine the levels of fibrinogen and haemoglobin in HIV-positive patients. According to our results, the mean and standard deviation of fibrinogen levels in HIV patients was statistically considerably greater than in the healthy control group. In contrast to A. Abdollahi et al., who showed that of the 228 subjects, 137 (61\%) were male and 69 (39\%) were female, with an average age of 37.48 years, and reported that hematological parameters and plasma fibrinogen levels were significant $(\mathrm{P}$-value $<0.0001)$ reduced in the HIV group compared with the control group [20]. Our findings contradicted a recent study in Nigeria by Okoroiwu Leticia [21], who looked at fibrinogen and factor VIII levels in 164 people, including $114 \mathrm{HIV}$ positive people and $50 \mathrm{HIV}$ negative people who served as controls, and found no significant difference in fibrinogen levels in HIV patients compared to normal people (P-value $>0.05$ ). The discrepancies between our patients and those in the aforementioned studies could be related to the methodologies utilized or the duration of disease in our individuals. The findings of this study were compatible with those of Lijfering et al. [22], who reported that HIV-positive patients have higher amounts of fibrinogen in their blood than HIV-negative people in a study of $109 \mathrm{HIV}$-infected patients. The intriguing findings of the study were similar to a variety of theories presented to explain the observed hypercoagulability in HIV-positive patients with elevated D dimer levels and decreased natural anticoagulant levels [23] [24]. We hypothesized that AIDS patients release cytokines that activate the coagulation system, leading to an increase in fibrinogen serum levels. Protein $\mathrm{C}$ and protein $\mathrm{S}$ are important physiologic coagulation inhibitors. While both proteins are synthesized by hepatocytes in the presence of vitamin $\mathrm{K}$, protein $\mathrm{S}$ additionally is produced by endothelial cells and megakaryocytes [25]. The current study discovered that protein $\mathrm{C}$ levels were deficient in 16 percent of HIV patients (8/50); this finding was consistent with many other authors who reported that protein $\mathrm{C}$ deficiency is detected in 0 percent to 14 percent of individuals [26] [27] [28] [29]. Our findings corroborate that of Khare, Swati, et al. (2018), who observed that HIV-positive patients had lower haemoglobin, platelet counts, mean platelet volume, protein $\mathrm{C}$, and S activity than healthy people [30]. Protein $\mathrm{C}$ levels that are down regulated in HIV patients have been linked to an increased risk of venous thrombosis [31] [32] [33]. Our observation supports a number of studies that looked into how HIV-positive patients' hemostasis is altered [34] [35]. The source of these acquired coagulation inhibitor deficiencies in HIV-positive patients is unknown, but acute opportunistic infections may cause 
a drop in protein $\mathrm{S}$ and protein $\mathrm{C}$ levels. Anemia is common among HIV-positive patients, but its complex cause makes differential diagnosis and appropriate therapy difficult [36]. This study shows that the haemoglobin levels were statistically significantly lower in HIV-positive patients when compared to the normal healthy control group P-value 001. This finding was in concordance with Daniel et al. [37] found that hemoglobin levels, Red Blood Cell count, Haematocrit, Mean Cell Volume and Mean Cell Hemoglobin were significantly reduced with a p-value $>0.05$ in a case-control study of 150 HIV seropositive patients on antiretroviral treatment and 50 HIV seronegative control patients. Friel and Scadden [38] also discovered that HIV-positive patients' hemoglobin levels were much lower. According to the findings of this study, people who have HIV are substantially more prone to acquire anemia [39] [40] [41]. The mean of Erythrocyte sedimentation rate in HIV patients was statistically significantly $(P>0.001)$ higher compared with normal healthy, these results confirm that findings reported in Ghana [37] Nigeria [42]. Our study was harmonized with the fact that ESR is frequently elevated in infections and inflammatory disorders such as HIV. The elevated ESR in these settings is related to increased production of acute-phase proteins and releases of proteins by the pathogenic organism into the circulation [43].

\section{Limitation of the Study}

The small sample size and short study time are the two most significant limitations of this study.

\section{Conclusion}

According to our findings, plasma fibrinogen levels in HIV-positive people were significantly greater, along with lower plasma protein $\mathrm{C}$ levels, than in healthy people, indicating a hypercoagulable state that is likely to increase the risk of thrombosis. HIV patients developed anemia as a result of the infection if their haemoglobin level decreased below $11 \mathrm{~g} / \mathrm{dl}$, depending on the hemoglobin result. When compared to normal healthy control group, our HIV-positive patients exhibited a higher ESR.

\section{Research Funding}

This research was supported by the Empower Women for Change Organization in Glasgow, Scotland.

\section{Authors Contributions}

All authors listed have made a substantial, direct and intellectual contribution to the work, and approved it for publication.

\section{Data Availability}

The paper includes all datasets created or analyzed during the research. 


\section{Conflicts of Interest}

There are no conflicts of interest declared by the authors.

\section{References}

[1] Levy, J.A. (2009) HIV Pathogenesis: 25 Years of Progress and Persistent Challenges. AIDS, 23, 147-160. https://doi.org/10.1097/QAD.0b013e3283217f9f

[2] Hankins, C. (2017) Review of HIV in Sub-Saharan Africa: Current Situation, Opportunities and Challenges. BMJ Global Health, 2, A3. https://doi.org/10.1136/bmigh-2016-000260.4

[3] Levine, A.M., Karim, R., Mack, W., Gravink, D.J., Anastos, K., Young, M., Cohen, M., Newman, M., Augenbraun, M., Gange, S. and Watts, D.H. (2006) Neutropenia in Human Immunodeficiency Virus Infection: Data from the Women's Interagency HIV Study. Archives of Internal Medicine, 166, 405-410. https://doi.org/10.1001/archinte.166.4.405

[4] Berhane, K., Karim, R., Cohen, M.H., Masri-Lavine, L., Young, M., Anastos, K., Augenbraun, M., Watts, D.H. and Levine, A.M. (2004) Impact of Highly Active Antiretroviral Therapy on Anemia and Relationship between Anemia and Survival in a Large Cohort of HIV-Infected Women: Women's Interagency HIV Study. JAIDS Journal of Acquired Immune Deficiency Syndromes, 37, 1245-1252. https://doi.org/10.1097/01.qai.0000134759.01684.27

[5] Alexaki, A. and Wigdahl, B. (2008) HIV-1 Infection of Bone Marrow Hematopoietic Progenitor Cells and Their Role in Trafficking and Viral Dissemination. PLOS Pathogens, 4, e1000215. https://doi.org/10.1371/journal.ppat.1000215

[6] Kannel, W.B. (2005) Overview of Hemostatic Factors Involved in Atherosclerotic Cardiovascular Disease. Lipids, 40, 1215-1220.

https://doi.org/10.1007/s11745-005-1488-8

[7] Tracy, R.P. (1999) Inflammation Markers and Coronary Heart Disease. Current Opinion in Lipidology, 10, 435-441. https://doi.org/10.1097/00041433-199910000-00008

[8] Danesh, J., Lewington, S., Thompson, S.G., et al. (2005) Plasma Fibrinogen Level and the Risk of Major Cardiovascular Diseases and Nonvascular Mortality: An Individual Participant Meta-Analysis. JAMA, 294, 1799-1809.

https://doi.org/10.1001/jama.294.14.1799

[9] Shah, I. (2016) Protein S and Protein C Deficiency with Multiple Infarcts in a Human Immunodeficiency Virus-Infected Female Child. Indian Journal of Sexually Transmitted Diseases and Aids, 37, 190-192. https://doi.org/10.4103/0253-7184.192119

[10] Jackson, B.S., Nunes Goncalves, J. and Pretorius, E. (2020) Comparison of Pathological Clotting Using Haematological, Functional and Morphological Investigations in HIV-Positive and HIV-Negative Patients with Deep Vein Thrombosis. Retrovirology, 17, Article No. 14. https://doi.org/10.1186/s12977-020-00523-3

[11] Matta, F., Yaekoub, A.Y. and Stein, P.D. (2008) Human Immunodeficiency Virus Infection and Risk of Venous Thromboembolism. The American Journal of the Medical Sciences, 336, 402-406. https://doi.org/10.1097/MAJ.0b013e31816dd2fd

[12] Copur, A.S., Smith, P.R., Gomez, V., Bergman, M. and Homel, P. (2002) HIV Infection Is a Risk Factor for Venous Thromboembolism. AIDS Patient Care and STDs, 16, 205-209. https://doi.org/10.1089/10872910252972258

[13] Sullivan, P.S., Dworkin, M.S., Jones, J.L. and Hooper, W.C. (2000) Epidemiology of 
Thrombosis in HIV-Infected Individuals. The Adult/ Adolescent Spectrum of HIV Disease Project Aids, 14, 321-324. https://doi.org/10.1097/00002030-200002180-00015

[14] Fultz, S.L., McGinnis, K.A., Skanderson, M., Ragni, M.V. and Justice, A.C. (2004) Association of Venous Thromboembolism with Human Immunodeficiency Virus and Mortality in Veterans. The American Journal of Medicine, 116, 420-423. https://doi.org/10.1016/j.amjmed.2003.10.011

[15] Hsue, P.Y., Giri, K., Erickson, S., MacGregor, J.S., Younes, N., Shergill, A. and Waters, D.D. (2004) Clinical Features of Acute Coronary Syndromes in Patients with Human Immunodeficiency Virus Infection. Circulation, 109, 316-319. https://doi.org/10.1161/01.CIR.0000114520.38748.AA

[16] Hsue, P.Y., Lo, J.C., Franklin, A., Bolger, A.F., Martin, J.N., Deeks, S.G. and Waters, D.D. (2004) Progression of Atherosclerosis as Assessed by Carotid Intima-Media Thickness in Patients with HIV Infection. Circulation, 109, 1603-1608. https://doi.org/10.1161/01.CIR.0000124480.32233.8A

[17] Tabib, A., Leroux, C., Mornex, J.F. and Loire, R. (2000) Accelerated Coronary Atherosclerosis and Arteriosclerosis in Young Human-Immunodeficiency-Virus-Positive $\mathrm{Pa}$ tients. Coronary Artery Disease, 11, 41-46. https://doi.org/10.1097/00019501-200002000-00008

[18] Triant, V.A., Lee, H., Hadigan, C. and Grinspoon, S.K. (2007) Increased Acute Myocardial Infarction Rates and Cardiovascular Risk Factors among Patients with Human Immunodeficiency Virus Disease. The Journal of Clinical Endocrinology \& Metabolism, 92, 2506-2512. https://doi.org/10.1210/jc.2006-2190

[19] Kuller, L.H., Tracy, R., Belloso, W., De Wit, S., Drummond, F., Lane, H.C., Ledergerber, B., Lundgren, J., Neuhaus, J., Nixon, D., Paton, N.I., Neaton, J.D. and INSIGHT SMART Study Group (2008) Inflammatory and Coagulation Biomarkers and Mortality in Patients with HIV Infection. PLOS Medicine, 5, e203.

https://doi.org/10.1371/journal.pmed.0050203

[20] Abdollahi, A., Shoar, N., Shoar, S. and Rasoulinejad, M. (2013) Extrinsic and Intrinsic Coagulation Pathway, Fibrinogen Serum Level and Platelet Count in HIV Positive Patients. Acta Medica Iranica, 51, 472-476.

[21] Leticia, O.I., Ugochukwu, A., Ifeanyi, O.E. andrew, A. and Ifeoma, U.E. (2014) The Correlation of Values of Cd4 Count, Platelet, Pt, Aptt, Fibrinogen and Factor VIII Concentrations among HIV Positive Patients in FMC Owerri. Journal of Dental and Medical Sciences, 13, 94-101. https://doi.org/10.9790/0853-139294101

[22] Lijfering, W.M., Sprenger, H.G., Georg, R.R., van der Meulen, P.A. and van der Meer, J. (2008) Relationship between Progression to AIDS and Thrombophilic Abnormalities in HIV Infection. Clinical Chemistry, 54, 1226-1233.

https://doi.org/10.1373/clinchem.2008.103614

[23] Shen, Y.-M.P. and Frenkel, E.P. (2004) Trombosis and a Hypercoagulable State in HIV-Infected Patients. Clinical and Applied Trombosis/ Hemostasis, 10, 277-280. https://doi.org/10.1177/107602960401000311

[24] Himmat, W. and Gaufri, N. (2016) Estimation and Assessment of Plasma D-Dimer Levels in HIV Patients. Journal of Biosciences and Medicines, 4, 1-5. https://doi.org/10.4236/jbm.2016.410001

[25] Fair, D.S. and Marlar, R.A. (1986) Biosynthesis and Secretion of Factor VII, Protein C, Protein S, and Protein C Inhibitor from a Human Hepatoma Cell Line. Blood, 67, 64-70. https://doi.org/10.1182/blood.V67.1.64.64

[26] Stahl, C.P., Wideman, C.S., Spira, T.J., Haff, E.C., Hixon, G.J. and Evat, B.L. (1993) 
Protein S Deficiency in Men with Long-Term Human Immunodeficiency Virus Infection. Blood, 81, 1801-1807. https://doi.org/10.1182/blood.V81.7.1801.1801

[27] Bissuel, F., Berruyer, M., Causse, X., Dechavanne, M. and Trepo, C. (1992) Acquired Protein S-Deficiency: Correlation with Advanced Disease in HIV-1-Infected Patients. JAIDS Journal of Acquired Immune Deficiency Syndromes, 5, 484-489. https://doi.org/10.1097/00126334-199205000-00009

[28] Sorice, M., Griggi, T., Arcieri, P., Circella, A., d'Agostino, F., Ranieri, M., Modrzewska, R., Lenti, L. and Mariani, G. (1994) Protein S and HIV Infection, Role of Anticardiolipin and Anti-Protein S Antibodies. Thrombosis Research, 73, 165-175. https://doi.org/10.1016/0049-3848(94)90095-7

[29] Brew, B.J. and Miller, J. (1996) Human Immunodeficiency Virus Type 1-Related Transient Neurological Deficits. The American Journal of Medicine, 101, 257-261. https://doi.org/10.1016/S0002-9343(96)00123-4

[30] Khare, S., Kushwaha, R., Kumar, A., Venkatesh, V., Reddy, H.D., Jain, M., Yusuf, M. and Singh, U.S. (2018) Prothrombotic State in HIV: A Study on Protein C, Protein S, Homocysteine and Correlation with CD4 Counts. Indian Journal of Medical Microbiology, 36, 201-206. https://doi.org/10.4103/ijmm.IJMM 15414

[31] Eyal, A. and Vella, M. (2009) HIV and Venous Thrombotic Events. South African Journal of Surgery, 7, 93-95.

[32] Opie, J. (2012) Haematological Complications of HIV Infection. The South African Medical Journal, 102, 465-468. https://doi.org/10.7196/SAMJ.5595

[33] Katie, K. and Melissa, B. (2011) Risk Factors for Venous Thromboembolism in Patients with HIV-Infection. Pharmacotherapy, 30, 1293-1304.

[34] Arildsen, H., Sørensen, K.E., Ingerslev, J.M., Østergaard, L.J. and Laursen, A.L. (2013) Endothelial Dysfunction, Increased Inflammation, and Activated Coagulation in HIV-Infected Patients Improve after Initiation of Highly Active Antiretroviral Therapy. HIV Medicine, 14, 1-9. https://doi.org/10.1111/j.1468-1293.2012.01027.x

[35] Mari, D., Coppola, R. and Provenzano, R. (2008) Hemostasis Factors and Aging. Experimental Gerontology, 43, 66-73. https://doi.org/10.1016/j.exger.2007.06.014

[36] Kreuzer, K.A. and Rockstroh, J. (1997) Pathogenesis and Pathophysiology of Anemia in HIV Infection. Annals of Hematology, 75, 179-187. https://doi.org/10.1007/s002770050340

[37] Tagoe, D.N.A. and Asantewaa, E. (2011) Profiling Haematological Changes in HIV Patients Attending Fevers Clinic at the Central Regional Hospital in Cape Coast, Ghana: A Case-Control Study. Archives of Applied Science Research, 3, 326-331.

[38] Friel, J.T. and Scadden, T.D. (2011) Haematological Manifestations of HIV Infection.

http://www.uptodate.com/contents/hematologic-manifestations-of-hiv-infection-an emia

[39] Maddrey, W.C. (1999) Safety of Combination Interferon alfa-2b/Ribavirin Therapy in Chronic Hepatitis C-Relapsed and Treatment-Naive Patients. Seminars in Liver Disease, 19, 67-75.

[40] Levine, A.M., Berhane, K., Masri-Lavine, L., Sanchez, M., Young, M., Augenbraun, M., Cohen, M., Anastos, K., Newman, M., Gange, S.J. and Watts, H. (2001) Prevalence and Correlates of Anemia in a Large Cohort of HIV-Infected Women: Women's Interagency HIV Study. JAIDS Journal of Acquired Immune Deficiency Syndromes, 26, 28-35. https://doi.org/10.1097/00042560-200101010-00004 
[41] Sullivan, P.S., Hanson, D.L., Chu, S.Y., Jones, J.L. and Ward, J.W. (1998) Epidemiology of Anemia in Human Immunodeficiency Virus (HIV)-Infected Persons: Results from the Multistate Adult and Adolescent Spectrum of HIV Disease Surveillance Project. The Adult/Adolescent Spectrum of Disease Group. Blood, 91, 301-308. https://doi.org/10.1182/blood.V91.1.301

[42] Ifeanyichukwu, O.M., Bright, E.O., Meludu, S.C. and Okeke, C.O. (2016) Effect of HIV Infection on Some Haematological Parameters and Immunoglobulin Levels in HIV Patients in Benin City, Southern Nigeria. Journal of HIV \& Retrovirus, 2, 2. https://doi.org/10.21767/2471-9676.100017

[43] Akpan, P.A., Akpotuzor, J.O. and Akwiwu, E.C. (2012) Some Hematological Parameters of Tuberculosis (TB) Infected Africans: The Nigerian Perspective. Journal of Natural Sciences Research, 2, 50-56. 